\title{
ADENOCARCINOMA ENDOMETRIAL METASTÁSICO A UN DEDO
}

\author{
Constanza Franco MD*; Edgardo Yaspe MD**, Rafael Parra Medina MD***
}

\section{Resumen}

Las metástasis cutáneas pueden ocurrir como primera manifestación de un carcinoma primario desconocido. Su presentación es rara, pueden debutar como un cuadro infeccioso, doloroso y son de mal pronóstico. Los tumores primarios más frecuentes que pueden comprometer la piel son de mama, pulmón, riñón y tracto gastrointestinal. El siguiente caso es de una paciente con metástasis de origen endometrial al primer dedo de la mano derecha.

Palabras clave: metástasis, adenocarcinoma, endometrio, cutánea.

\section{ENDOMETRIAL ADENOCARCINOMA METASTATIC TO A FINGER}

\section{Abstract}

Cutaneous metastases may occur as the initial manifestation of primary internal malignancy. They are uncommon and may present initially as a painful infectious lesion with poor prognosis. Breast, lung, kidney and gastrointestinal primary tumors are the commonest malignancies metastasizing to the skin. The following case corresponds to a woman who developed a cutaneous metastasis on the first finger of the right hand in relation to her initial endometrial cancer.

Key words: metastasis, adenocarcinoma, endometrium, cutaneous

\section{Introducción}

Las metástasis cutáneas son una manifestación rara de un tumor maligno primario desconocido, y se pueden manifestar como un cuadro infeccioso. Los tumores malignos que más lo hacen son los de mama, pulmón, riñón y menos común los de origen gastrointestinal. ${ }^{1}$ El compromiso cutáneo por carcinoma de endometrio suele ocurrir en lugares cercanos como vulva y vagina, pero a distancia es exótico.

\section{Caso clínico}

Paciente de 66 años que consulta por dolor severo en primer dedo de la mano derecha secundario a trauma. Se realizó drenaje de la lesión interpretada como he-
Fecha recibido: junio 4 de 2014 - Fecha aceptado: julio 10 de 2014

* Residente III de Patología, Fundación Universitaria de Ciencias de la Salud. Bogotá DC, Colombia.

\footnotetext{
** Patólogo oncólogo. Profesor Asistente, Fundación Universitaria de Ciencias de la Salud. Bogotá DC, Colombia.

*** Residente I de Patología, Fundación Universitaria de Ciencias de la Salud. Bogotá DC, Colombia.
} 
matoma y el material fue enviado a patología donde se diagnosticó un carcinoma metastásico. Se tomó radiografía que muestra una lesión lítica en la falange distal. Dentro de los antecedentes de importancia estaba cáncer de endometrio previo e histerectomía abdominal ampliada. En el examen físico se encontró en la falange distal colección con signos de sufrimiento en la piel y dolor a la palpación. Con el reporte de patología y los hallazgos clínicos e imagenológicos se sospechó metástasis y se decidió llevar a cirugía.

En el servicio de patología se recibió producto de amputación a nivel de la articulación metacarpofalángica. En la superficie externa se observó ensanchamiento de los dos tercios distales de coloración violácea (Figura 1). A los cortes transversales se identificó una masa friable, de consistencia blanda de 4x4 cm que ocupaba la dermis, el tejido celular subcutáneo y todos los compartimentos, con destrucción total de las falanges media y distal. Al microscopio se vió una lesión tumoral maligna de células grandes con núcleos pleomórficos, nucléolos prominentes, que forman acinos y mitosis atípicas, de tipo adenocarcinoma moderadamente diferenciado con áreas de patrón endometrioide e invasión vascular que compromete la dermis y el tejido celular subcutáneo (Figura 2). Se realizaron estudios de inmunohistoquímica los cuales mostraron positividad en las células tumorales para queratinas AE1/AE3, CK 7, CEA, beta catenina y vimentina, con negatividad para CK 20, estrógenos y GCDFP-15 (Figura 3). Los hallazgos histológicos y la inmunohistoquímica favorecieron una metástasis de origen primario en endometrio.

\section{Disc usión}

Las metástasis cutáneas representan el 2\% de todas las neoplasias ${ }^{2}$ y por lo regular aparecen de forma tardía o como presentación inicial del tumor primario. ${ }^{3} \mathrm{De}$ estos, las más frecuentes que pueden comprometer la piel son de mama, riñón y tracto gastrointestinal. ${ }^{2} \mathrm{El}$ adenocarcinoma de endometrio puede afectar la piel en cerca de $0.8 \%{ }^{4}$ en especial en zonas cercanas como vulva y vagina. ${ }^{5}$ Las metástasis pueden ser nódulos, pápulas, úlceras, placas o masas, siendo más común las primeras. El tamaño varía entre 1 y $3 \mathrm{~cm}$ y suelen tener un crecimiento rápido. ${ }^{6}$ En la histología afectan la dermis y pueden tener un patrón nodular, infiltrante, difuso o intravascular. ${ }^{6}$ Casi siempre las de origen endometrial se localizan en el tejido celular subcutáneo

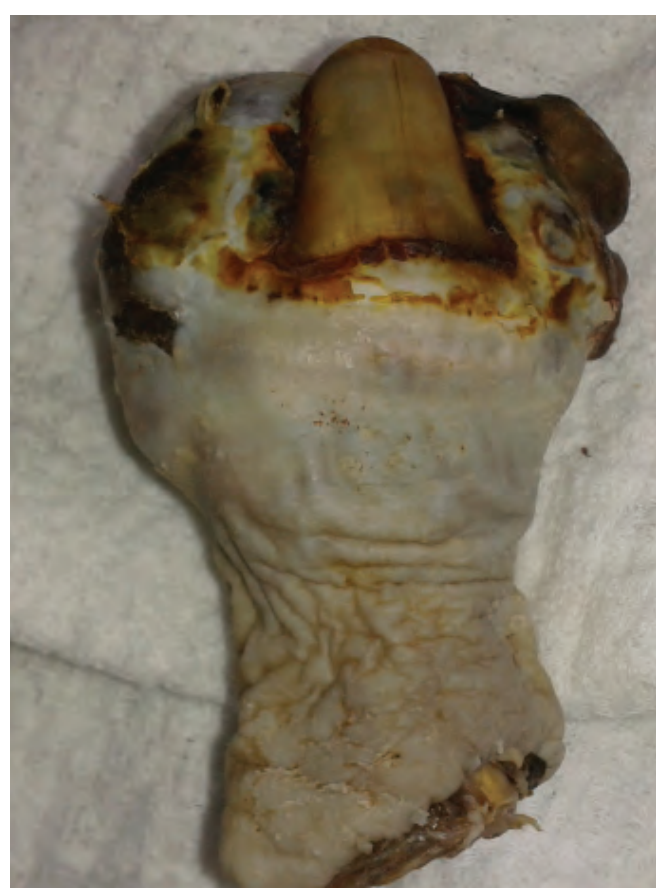

Figura.I. Producto de amputación metacarpofalángica.

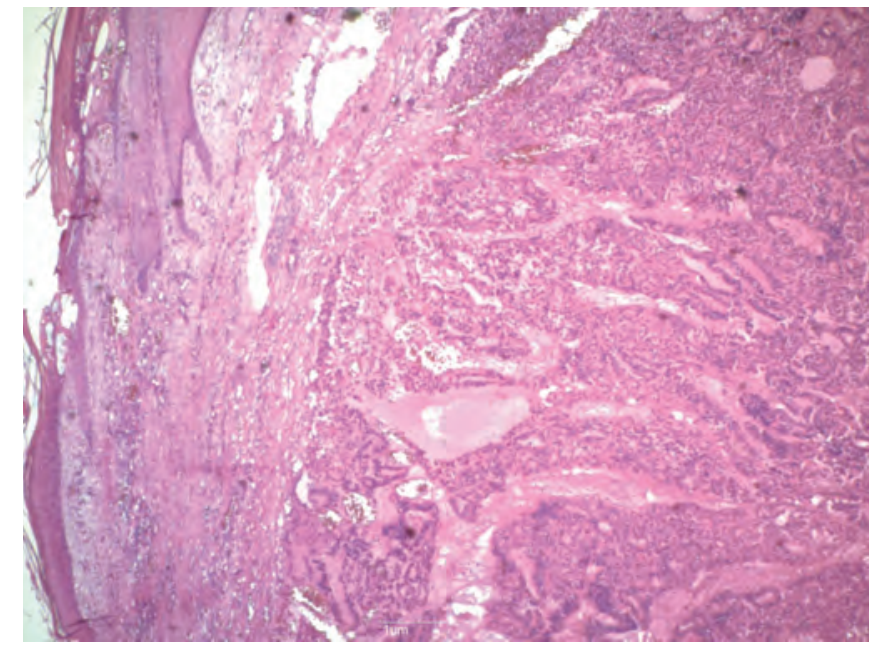

Figura 2. Con la coloración H-E la imagen muestra epidermis de aspecto normal. En la dermis hay una lesión tumoral maligna de células grandes con núcleos pleomórficos, nucléolos prominentes que forman acinos, con mitosis atípicas, características de un adenocarcinoma moderadamente diferenciado. 
y son masas no dolorosas a la palpación. ${ }^{7}$ La presencia de metástasis en los dedos por adenocarcinoma endometrial es extremadamente rara y a menudo la invasión tumoral se inicia como compromiso óseo hasta invadir la epidermis. ${ }^{8}$

Los tumores endometriales con compromiso de la piel tienen mal pronóstico debido al tiempo transcurrido entre el diagnóstico del tumor y el compromiso cutáneo. ${ }^{9}$ En este caso se inició la búsqueda del primario a partir de la metástasis, para lo cual se realizaron estudios de inmunohistoquímica. La recomendación para el tratamiento es la resección de la lesión, sin embargo por el compromiso que tienen estos pacientes el manejo se convierte en paliativo. ${ }^{10}$

$\mathrm{Al}$ sospechar un carcinoma de origen primario desconocido, la identificación se enfoca por las características histológicas y la inmunohistoquimica, analizando la expresión de los antígenos. En este caso la positividad para CK7, betacatenina, CEA, vimentina y sin expresión de CK20 y GCDFP-15, descartaron el origen en colon o mama y favorecieron el de endometrio. ${ }^{11,12}$

\section{Conclusión}

Las metástasis cutáneas de carcinoma de endometrio son raras y con compromiso a dedo son exóticas. Los hallazgos histológicos y el perfil de inmunohistoquímica favorecieron el origen endometrial y descartaron el origen en colon o mama. ${ }^{11,12}$

\section{Referencias}

1. Diez Recio E, Sanchez Herreros C. Metástasis cutáneas de presentación atípica de adenocarcinoma de probable prigen endometrial. Med Cutan Iber Lat Am. 2009; 37(4):184-8.

2. Nashan D, Meiss F, Braun-Falco M, Reichenberger S. Cutaneous metastases from internal malignancies. Dermatol Ther. 2010;23(6):567-80

3. Schwartz RA. Cutaneous metastatic disease. J Am Acad Dermatol. 1995 Aug; 33(2 Pt 1):161-82.

4. Lerner LB, Andrews SJ, Gonzalez JL, Heaney JA, Currie JL. Vulvar metastases secondary to transitional cell carcinoma of the bladder. A case report. J Reprod Med. 1999 Aug; 44(8):729-32.

5. Atallah D, el Kassis N, Lutfallah F, Safi J, Salameh C, Nadiri S, et al. Cutaneous metastasis in endometrial cancer: once in a blue moon - case report. World J Surg Oncol. 2014 Jan; 12:86.

6. Fernandez-Flores A. Cutaneous metastases: a study of 78 biopsies from 69 patients. Am J Dermatopathol. 2010 May; 32(3):222-39.

7. Zahra F, El M, Hottinger A, Claude A. Cutaneous Metastasis of Endometrial Carcinoma: A Case Report and Literature Review. J Clin Gynecol Obstet. 2012;1(1):19-23

8. Cohen PR. Metastatic tumors to the nail unit: subungual metastases. Dermatol Surg. 2001 Mar; 27(3):280-93

9. Elit L, Lukka H, Friedman E. Cutaneous metastasis of papillary serous uterine cancer. Gynecol Oncol. 2001 Jul; 82(1): 208-11.

10. Awtrey CS, Cadungog MG, Leitao MM, Alektiar KM, Aghajanian C, Hummer AJ, et al. Surgical resection of recurrent endometrial carcinoma. Gynecol Oncol. 2006 Sep;102(3):480-8.

11. Kurman RJ, Hedrick Ellenson L, Ronnett BM, editors. Blaustein's Pathology of the female genital tract. 6th ed. New York: Springer; 2011.

12. Susan C. Lester SC. Manual of surgical pathology. 3rd ed. Philadelphia: Elsevier; 2010. 